\title{
SUCCESS RATE OF ONE SESSION AND TWO SESSION TECHNIQUES FOR TREATMENT OF ASYMPTOMATIC PULPITIS OF PRIMARY TEETH WITH INDIRECT PULP CAPPING
}

\author{
Rossitza Kabaktchieva ${ }^{1}$, Natalia Gateva ${ }^{1}$, Kremena Nikolova ${ }^{2}$ \\ 1) Department of Pediatric Dentistry, Faculty of Dental Medicine, Medical \\ University, Sofia, Bulgaria, \\ 2) Working in private dental practice
}

\section{SUMMARY:}

Objective: To compare the success rate between the one session and two session indirect pulp capping of asymptomatic pulpitis for 1 year after the treatment was performed in children with different caries risk.

Material and Methods: The children and the teeth were selected according to certain criteria for inclusion in the study. According to that, 72 children with low, moderate and high caries risk were included and 131 teeth with asymptomatic pulpitis were treated. The clinical protocols for indirect pulp capping (IPC) in one session and two sessions were defined. The review appointments were performed 6 and 12 months after the treatment using certain clinical and radiographic criteria which defined success or post-treatment complications. The results are statistically analysed using One Sided Exact Two-Proportion Test with 95\% Significance level (5\% risk of type I error).

Results: The statistical test showed that between the compared success rates of the one session and two sessions IPC, on the $6^{\text {th }}$ and $12^{\text {th }}$ month, there wasn't a significant difference $(p>0.05)$. This was valid for every one of the examined groups of patients $(p>0.05)$. This proves that there is no difference in the success rates of treatment of pulpitis in primary teeth using one or two sessions.

Conclusions: The results about the success of treatment of asymptomatic pulpitis in primary teeth during one or two sessions have confirmed the results showed in other current studies. Our study has confirmed (clinically and radiographically) the success of both techniques and we have concluded that in children with high caries risk, more appropriate technique is the one performed in two sessions. Treatment in one session is recommended in children with low or moderate caries risk.

Key words: indirect pulp capping, asymptomatic pulpitis, primary teeth

A trend in the contemporary dentistry is microinvasive approach in operative caries treatment $(6,7)$.
The agreed consensus in Bulgaria is to apply a microinvasive approach - indirect pulp capping (IPC) for treatment of asymptomatic pulpitis (1). This is the most common pulpitis in primary teeth. The diagnosis of asymptomatic pulpitis (reversible pulpitis) is based on actual clinical, symptomatic and radiographic signs $(2,17,19)$.

IPC for pulp treatment is recommended on evidence based grounds about the defensive abilities of the pulp in primary teeth $(10,14,18)$.

Indirect Pulp Therapy (IPT) is a treatment method, which aims to protect the pulp from exposure, favourably affects its inflammation indirectly, and as a result preserves the vitality of the pulp $(2,14,17)$.

Special approach is required in order to protect the pulp from exposure: initially, removal of the infected dentin layer by layer and preservation of the remineralised dentin above the pulp when the cavity is re-opened (stepwise/two session technique), or removal of the infected dentin and preservation of a thin layer of demineralised dentin above the pulp in one session (one session technique) $(7,14)$. Both IPC techniques relay on, pulp to be protected by a partially remineralised overpulpal demineralised dentin (produced by using $\mathrm{Ca}(\mathrm{OH})_{2}$ ) and reactive dentin formed underneath it. (3).

For the past few years, IPC in primary teeth has been studied and discussed a lot to find out if the partially remaining infected dentin above the pulp which subsequently remineralises, after few months without symptoms, should be removed or not, in another words - if the tooth should be re-opened for additional excavation or the treatment could be performed in one treatment session $(7,8,9,14$, 15). To decide which option is the best, microbiological studies could be very helpful. They show that the bacteria counts in the carious dentine at the bottom of the cavity during the two session technique is comparable with the one of the demineralised dentin layer during the one session technique $(11,12,15,16)$. No difference of the carious lesion progression is observed, no matter of the technique used (16). 
The current trend for minimal invasive approach for treatment of primary teeth and the facts known by far about the IPC treatment of teeth with asymptomatic pulpits, determined the aim of our study: to compare the success rate between the one session and two session indirect pulp capping of asymptomatic pulpitis for 1 year after the treatment was performed in children with different caries risk.

\section{MATERIAL AND METHODS:}

The children and the teeth were selected according to pre-determined criteria for inclusion in the study. According to that, 72 children with low, moderate and high caries risk were included and 131 teeth with asymptomatic pulpitis were treated.

\section{Criteria for selection of children:}

- somatically healthy children aged 4-8 years with the presence of visually determined deep carious lesion/ lesions of primary teeth;

- children were divided into basic groups according to the risk assessment of caries development;

- children with no history of drug and food allergies;

- children with no history of previous or current spontaneous pain related with carious tooth.

- children who have definitely positive or positive attitude towards dental treatment.

\section{Criteria for selection of primary tooth/ teeth:}

Clinical findings:

- tooth with large cavitated carious lesion and soften lighter or darker carious dentin without pulp exposure (closed pulpitis).

- tooth with no evidence of fistula or previously conducted treatment;

- tooth suitable for restoration with adhesive filling.

Symptoms:

- tooth with no pain symptoms - no night pain and spontaneous pain;

- pain to cold, sweet and pressure while chewing, which disappear after removing the irritation may present

Imaging - Diagnostic Bitewing (BW) Radiography

- tooth with carious lesion in the inner third of the dentin and close to the pulp, without exposure of the pulp chamber;

- tooth with physiological root resorption up to $\mathrm{S}$ of the length of the root / roots;

- tooth with no pathological intrapulpal resorption or resorption inside the root. sessions:

Clinical protocol for implementation of IPC in two

Treatment protocol involved a two-stage removal of carious dentin. The logic of the approach is that after partial removal of infected dentin (in the first session using machine or hand excavator) and placement of $\mathrm{Ca}(\mathrm{OH})_{2}$, the bacteria counts in carious lesions decreases. Sealing of the cavity insulates the bacteria from their nutrition source and they die in the remained infected dentin. During the second session usually in 2 months we expect the underlying "affected dentin" to re-mineralise and below it to form a protective reactive dentin. Upon re-opening of the cavity the reactive dentin cavity makes the removal of residual carious dentin easier and safer.

\section{I session:}

1. Remove the carious dentin from the cavity walls and the gingival basis in interproximal defect (a round bur or excavator could be used).

2. Remove the dentin at the enamel-dentine border and underneath it, until sound, well-mineralised dentin is reached and the border is clearly visible.

3. Carefully remove the softest dentin at the bottom of the cavity with an excavator.

4. After the removal of the carious dentine the dental pulp could be found very close. Indirect pulp capping with $\mathrm{Ca}(\mathrm{OH})_{2}$ should be done.

5. Temporary dressing should be placed, ensuring sealing of the cavity - ZnO (IRM).

6 . The dressing should stay for 2 months.

\section{Session:}

1.Radiograph should be taken in 2 months to check the newly formed dentin above the pulp (as a result of remineralisation of demineralised dentin and formation of protective reactive dentin).

2. The temporary dressing is removed and the cavity is washed and dried.

3. Inspection of the dentin left over the pulp is performed.

4. Remove the superficial layer of demineralised dentine which was left, without removing layers of the remineralised dentin.

5. New capping with $\mathrm{Ca}(\mathrm{OH})_{2}$ is placed and proceed to the final restoration of the tooth. The tooth is filled with a self-etching adhesive system.

6. In case of Black's Class II cavity it is mandatory matrix band (Tofflemire) and matrix strip (Tofflemire matrix) to be used. session:

Clinical protocol for implementation of IPC in one

The treatment protocol involved removing of the infected carious dentin (infected dentin) and only the layer of demineralised dentin (affected dentin), which is close to the pulp was left. The pulp side was covered with $\mathrm{Ca}(\mathrm{OH})$ 2 material and the tooth was restored.

\section{Implementation of IPC:}

1. Application of local anaesthetic (if required); 
2. Isolation with cotton rolls and rubber dam (where possible);

3. Disclosure of carious lesions and removal of the infected carious dentin throughout the cavity (walls, EDB, gingival bottom). Only where the pulp wall is, a compromise is made and a thin layer of demineralised dentin that protects the pulp from disclosure could be retained;

4. Wash the cavity with saline and dry;

5. Cover the pulp wall with $\mathrm{Ca}(\mathrm{OH}) 2$ preparation Dycal (Densply)

6. The tooth is filled with a self-etching adhesive compomer system;

7. In case of Black's Class II cavity it is mandatory matrix band (Tofflemire) and matrix strip (Tofflemire matrix) to be used.

\section{Review:}

Clinical and radiographic reviews were performed in 6 and 12 months after treatment. The presence or absence of pain in the treated tooth was recorded.. The integrity of filling - preserved or impaired was assessed. Analysis of the $\mathrm{X}$-ray image of the tooth with the treatment was performed: presence of protective reactive dentin layer on the 6. month; presence of thickness of protective reactive dentin layer on the 12. month; presence of resorption in furcation areas and roots; obliteration of the root/roots;
Results assessment 6 and 12 months after treatment:

- Treatment was considered successful when clinical and radiographic characteristics were positive. Those cases were kept under review for the next 6 months.

- Treatment was considered failed when as a result the treatment protocol was changed or the tooth was extracted. Those cases were not reviewed.

For statistical analysis of the results we applied One Sided Exact Two-Proportion Test (with 95\% Significance level, $5 \%$ risk of type I error). The zero hypothesis is that the proportions of success in 2 session method are bigger than the proportions of success in 1 - session method, in other words, treatment in two sessions is better.

\section{RESULTS:}

Table 1 shows the number of treated primary teeth 131 with asymptomatic pulpitis (reversible pulpitis) distributed in groups - 24 children with low, moderate and high caries risk. After 6 and 12 months the teeth that meet the criteria for successfully conducted indirect pulp capping were evaluated. The success rate is presented in percentage to the number of teeth treated in the group.

Table 1. Results of success, 6 and 12 months after indirect pulp therapy (in one or two sessions) of asymptomatic pulpitis in primary teeth.

\begin{tabular}{|c|c|c|c|c|c|c|c|c|c|c|}
\hline \multirow{2}{*}{$\begin{array}{l}\text { Type of } \\
\text { treatment } \\
\text { Risk } \\
\text { groups }\end{array}$} & \multirow[b]{2}{*}{$\begin{array}{l}\text { Number } \\
\text { of children } \\
\text { treated }\end{array}$} & \multirow[b]{2}{*}{$\begin{array}{l}\text { Number } \\
\text { of teeth } \\
\text { treated }\end{array}$} & \multicolumn{3}{|c|}{ Treatment in 1 session } & \multicolumn{3}{|c|}{ Treatment in 2 sessions } & \multicolumn{2}{|c|}{$\begin{array}{c}\text { One Sided Exact } \\
\text { Two-Proportion } \\
\text { Test (p) }\end{array}$} \\
\hline & & & $\begin{array}{l}\mathrm{N} \text { of teeth } \\
\text { at the } \\
\text { beginning }\end{array}$ & $\begin{array}{c}6 \mathrm{~m} . \% \\
\text { success } \\
\text { rates }\end{array}$ & $\begin{array}{c}12 \mathrm{~m} . \% \\
\text { success } \\
\text { rates }\end{array}$ & $\begin{array}{c}\mathrm{N} \text { of teeth } \\
\text { at the } \\
\text { beginning }\end{array}$ & $\begin{array}{l}6 \mathrm{~m} . \% \\
\text { success } \\
\text { rates }\end{array}$ & $\begin{array}{c}12 \mathrm{~m} . \% \\
\text { success } \\
\text { rates }\end{array}$ & $6 \mathrm{~m}$ & $12 \mathrm{~m}$ \\
\hline Low risk & 24 & 24 & 12 & $100 \%$ & $100 \%$ & 12 & $100 \%$ & $100 \%$ & - & - \\
\hline Moderate risk & 24 & 49 & 26 & $\begin{array}{l}92 \% \\
* 1 \\
* * 1\end{array}$ & $92 \%$ & 23 & $\begin{array}{c}96 \% \\
* 1\end{array}$ & $96 \%$ & 0.313 & 0.313 \\
\hline High risk & 24 & 58 & 28 & $\begin{array}{l}86 \% \\
* 2 \\
* * 2\end{array}$ & $82 \%$ & 30 & $\begin{array}{c}93 \% \\
* 1 \\
* * 1\end{array}$ & $90 \%$ & 0.171 & 0.193 \\
\hline Total & 72 & 131 & 66 & $91 \%$ & $89 \%$ & 65 & $95 \%$ & $91 \%$ & 0.156 & 0.396 \\
\hline
\end{tabular}

* cases with complications $* *$ failed to attend the review appointment

The statistical test that was used showed that between the compared success rates of one session and two session IPC, on the 6th and 12th month, there wasn't a significant difference $(p>0.05)$. This was valid for every one of the examined groups of patients ( $p>0.05)$ (see fig. 1). In patients with low risk we achieved $100 \%$ success rate, no difference between the compared groups and the test can not be conducted, but the conclusion is the same. This proves that there is no difference in the success rates of treatment of pulpitis in primary teeth using one or two sessions. 
Fig. 1. Results of success of indirect pulp therapy for treatment of asymptomatic pulpitis in primary molars.

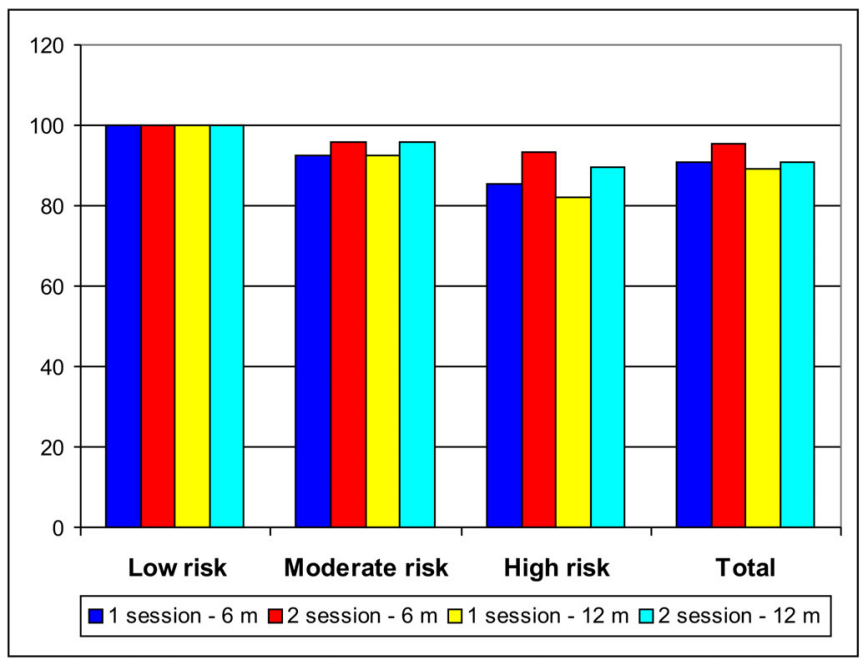

For the group of children with moderate caries risk the difference in success rates (on the 6. and 12. month) in 1 session and 2 session indirect treatment is statistically insignificant ( $p>0.05)$, with a slightly higher rate of success in 2 session approach (96\% to $92 \%)$. In the same group of patients treated in 1 session approach there was one tooth with complication (pulpotomy was performed) and one case that failed to attend the review appointment, while the teeth treated in 2 session approach there was only one tooth with complication (pulpotomy was performed). All results were found at review appointment on the 6 . month. The other teeth reviewed at the end of the first year met the clinical and radiographic criteria for successful indirect pulp therapy. This result indicates that indirect pulp therapy in one session or in two sessions are equally appropriate methods of treatment in primary teeth in children with moderate risk of developing caries. In the group of children with high risk of developing caries the difference in success rates (on the 6. and 12. month) in 1 session and 2 session IPC is statistically insignificant ( $p>0.05$ ), but with overweight of success rate in 2 session approach - (93\% to $86 \%$ in six months), and ( $90 \%$ to $82 \%$ in 12 months) (see high risk on Table 1 and Fig.1).

When the teeth were treated in 1 session approach there were two teeth with complication (pulpotomy was performed) and two cases failed to attend the review appointment, while the teeth treated in teeth in 2 sessions, only 1 tooth developed complications and 1 case failed to attend the review appointment. From the results we can conclude that indirect pulp therapy - 1 session or 2 session approach are equally appropriate in a group of children with high risk of developing caries and both have relatively high success rates.

\section{DISCUSSION:}

The results about the success rates (confirmed clinically and radiographically) of treatment of asymptomatic pulpitis in primary teeth during one or two sessions have confirmed the experience of other current researchers $(11,13$, $14,15)$. We couldn't find in the available literature a comparative study about the success rates between the two techniques in children with different caries risk. This is a fact that contributes to the originality of our study. Our clinical experience and the observation over the application of the two techniques of indirect pulp capping for treatment of asymptomatic pulpitis, have formed our opinion that in children with low caries risk, the two techniques are equally appropriate and no complications are to be expected. In children with moderate caries risk, again the two techniques are appropriate, with slightly higher success rate of 2 session method. In this group we observed also the same number of cases in which the treatment was not successful (there were complications), which were reported within the first few months. This failure could be explained with diagnostic mistake. In children with high caries risk, more appropriate technique is the one performed in two sessions, it shows reduced risk of complications, compare to higher risk of complications in 1 session technique, which were reported within the first few months after the treatment. Again, the complications could be explained with wrongly diagnosed asymptomatic pulpitis. The results could be explained also with the fact that in children with high caries risk the bacteria counts generally are greater, oral environment has proven to be more aggressive and the number of carious lesions is bigger. Most likely the 2 session approach would be more friendly to the patient and would give a chance the patient to be reviewed by a clinician for longer period of time.

\section{CONCLUSION:}

1. In children with low and moderate caries risk for the treatment of asymptomatic pulpitis we recommend one session technique of IPC. We share the opinion of other researchers that the one-session IPC is less risky in terms of cavity sealing, has high success rate $(100 \%$ in children with low risk and $92 \%$ in children with moderate risk) and saves time for clinicians and patients.

2. In children with high caries risk we recommend accuracy in diagnostic of asymptomatic pulpitis. When such a diagnosis present, the teeth could be treated in 2 session technique of IPC. Two session approach has higher success rate $(90 \%)$, is more friendly for the patient and give a chance the patient to be reviewed by a clinician for longer period of time.

Our study showed that indirect pulp therapy in primary teeth with asymptomatic pulpitis has high success rate and could be recommended in dental practice as a modern method of microinvasive treatment of primary teeth. 
Acknowledgements:

Financial support from the Medical Science Council (MU-Sofia) through Grant No. 19/2011 is gratefully acknowledged.

\section{REFERENCES:}

1. Bulgarian Association of Pediatric Dentistry Consensus for Treatment of pulpitis and periodontitis of primary teeth, First Symposium, Hisar, Bulgaria, 7-8 October, 2011(in Bulgarian).

2. American Academy of Pediatric Dentistry. Guideline on pulp therapy for primary and immature permanent teeth. Reference Manual 2009-10; 31: 179186.

3. Bjorndal L. Presence or absence of tertiary dentinogenesis in relation to caries progression. Adv Dent Res. 2001 Aug;15:80-83. [PubMed] [CrossRef]

4. Bjorndal L. Indirect pulp therapy and stepwise excavation. J Endod. 2008 Jul;34(7 Suppl):S29-33. [PubMed] [CrossRef]

5. Bjorndal L, Kidd EA. The treatment of deep dentine caries lesions. Dent Update. 2005 Sep;32(7): 402-4, 407-10, 413. [PubMed]

6. Duggal MS, Day PF. Pulp therapy in primary teeth. In: Paediatric Dentistry, Welbury, R.R., M.S. Duggal, M.T. Hosey, 4 ed., Oxford University Press, 2012, 132-138.

7. Ferreira JM, Pinheiro SL, Sampaio FC, de Menezes VA. Caries removal in primary teeth - a systematic review. Quintessence Int. 2012 Jan; 43(1):e9-15. [PubMed]

8. Fuks AB. Pulp therapy for the primary and young permanent dentitions. Dent Clin North Am 2000 Jul; 44(3): 571-596. [PubMed]

9. Kennedy DB, Kapala JT. The dental pulp: Biological principles of protection and treatment. In: Braham RL, Morris ME, eds. Textbook of Pediatric Dentistry. 2nd ed. Baltimore, Md: Williams and Wilkins; 1985:pp492502.

10. Kidd EA. How 'clean' must a cavity be before restoration? Caries Res. 2004 May-Jun;38(3):305-313. [PubMed] [CrossRef]

11. Lula EC, Monteiro-Neto V, Alves CM, Ribeiro CC. Microbiological analysis after complete or partial removal of carious dentin in primary teeth: A randomized clinical trial. Caries Res. 2009; 43(5):354-8. [PubMed] [CrossRef]

12. Magnusson BO, Sundell SO. Stepwise excavation of deep earious lesion in primary molars. Int $J$ Assoc Dent Child. 1977 Dec;8(2):36-40. [PubMed]

13. Orhan AI, Oz FT, Ozcelik B, Orhan K. A clinical and microbiological comparative study of deep carious lesion treatment in deciduous and young permanent molars. Clin Oral Investg. 2008 Dec;12(4):369-78. [PubMed] [CrossRef]

14. Orhan AI, Oz FT, Orhan K. Pulp exposure occurance and outcomes after 1-or 2-visit indirect pulp therapy vs complete caries removal in primary and permanent molars. Pediatr Dent. 2010 Jul-Aug;32(4): 347-355. [PubMed]

15. Ribeiro CC, de Oliveira Lula EC, da Costa RC, Nunes AM. Rationale for the partial removal of caries tissue in primary teeth. Pediatr Dent. 2012 Jan-Feb;34(1):39-41. [PubMed]

16. Rieketts DN, Kidd EA, Innes N, Clarkson J. Complete or ultraconservative removal of deeayed tissue in unfilled teeth. Coehrane Database Syst Rev. 2006 Jul 19;(3):CD003808. [PubMed] [CrossRef]

17. Rodd HD, Waterhouse PJ, Fuks AB, Fayle SA, Moffat MA. Pulp therapy for primary molars. Int J Paediatr Dent. 2006 Sep;16(Suppl 1):15-23. [PubMed] [CrossRef]

18. Tziafas D. Dentinogenic potential of the dental pulp: facts and hypotheses. Endod Topics. 2010 Sep; 17(1):42-64. [CrossRef]

19. Wambier DS, dos Santos FA, Guedes-Pinto AC, Jaeger RG, Simionato MR. Ultrastructural and microbiological analysis of the dentin layers affected by caries lesions in primary molars treated by minimal intervention. Pediatr Dent. 2007 May-Jun;29(3): 228-234. [PubMed]

\section{Corresponding author:}

Prof. Rossitza Kabaktchieva, PhD.

Department of Pediatric Dentistry, Faculty of dental medicine, Medical University, 1, St. George Sofiisky Blvd., 1431 Sofia, Bulgaria;

E- mail: r_kabaktchieva@mail.bg; 